\title{
PERANCANGAN SENSOR PENGUKUR KECEPATAN KAPSUL IRADIASI DI FASILITAS SISTEM RABBIT PNEUMATIK
}

\section{DESIGN OF PNEUMATIC IRRADIATION CAPSULES SPEED SENSORS IN PNEUMATIC SYSTEM RABBIT FACILITIES}

\author{
Hanapi Ali ${ }^{1}$, Kawkab Mustofa ${ }^{2}$, Sunarko ${ }^{3}$, Asnul Sufmawan ${ }^{4}$ \\ ${ }_{1,2,3,4}$ PRSG-BATAN Kawasan Puspiptek Gd. 30 Serpong, 15310 \\ Email : hanapiali@batan.go.id
}

Diterima: 2018, diperbaiki : 2018, disetujui : 2018

\begin{abstract}
ABSTRAK
PERANCANGAN SENSOR PENGUKUR KECEPATAN KAPSUL IRADIASI PNEUMATIK DI FASILITAS RABBIT SISTEM PNEUMATIK. Fasilitas iradiasi rabbit sistem pneumatik dikhususkan untuk mengiradiasi suatu spesimen atau sampel dengan waktu paruh pendek, sehingga dibutuhkan waktu transfer yang singkat dengan kecepatan transfer yang disyaratkan sebesar $10 \mathrm{~m} / \mathrm{s}$. Mengetahui kecepatan transfer kapsul bermanfaat dalam menentukan waktu iradiasi dan proteksi terhadap rusaknya kapsul tersebut karena tumbukan. Penelitian ini bertujuan untuk mengetahui perkiraan keakuratan sensor pengukur kecepatan yang dirancang. Dua buah sensor berbasis fotoelektrik digunakan untuk mengukur waktu layang atau Time of Flight (ToF) yang dibangkitkan oleh media yang diukur. Percobaan dilakukan menggunakan simulasi digital dengan perangkat lunak. Hasil percobaan menunjukkan hubungan antara waktu layang terhadap error pengukuran dan error kecepatan $10 \mathrm{~m} / \mathrm{s}$ sebesar 2\%. Error $2 \%$ didapatkan dari hasil pengolahan data secara statistik.
\end{abstract}

Kata Kunci : Rabbit sistem pneumatik, perancangan sensor kecepatan, waktu layang, foto elektrik, iradiasi

\begin{abstract}
DESIGN OF PNEUMATIC IRRADIATION CAPSULES SPEED SENSORS IN PNEUMATIC SYSTEM RABBIT FACILITIES. Pneumatic system rabbit irradiation facility is specialized to irradiate a specimen or sample with a short half-life, therefore a short transfer time is required with the required transfer speed of $10 \mathrm{~m} / \mathrm{s}$. Knowing the transfer rate of the capsule is useful to determine the irradiation time and protection against any damage to the capsule due to collisions. This study aims to determine the approximate accuracy of the designed speed measuring sensor. Two photoelectric based sensors are used to measure the Time of Flight (ToF) generated by the measured media. Experiments were carried out using digital simulations with software. The result of the experiments show the relationship between Time of flight (Tof) to the measurement error and error at a speed of $10 \mathrm{~m} / \mathrm{s}$ by $2 \%$. A $2 \%$ error is obtained from the results of statistical data processing.
\end{abstract}

Keywords: Rabbit pneumatic system, speed sensor design, Time of flight (ToF), photo electric, irradiation 


\section{PENDAHULUAN}

Fasilitas iradiasi rabbit sistem

(RS)

adalah salah satu fasilitas iradiasi yang digunakan untuk produksi radioisotop dan untuk penelitian dengan metode Analisis Aktivasi Neutron (AAN). Rabbit sistem memungkinkan operator melakukan iradiasi di teras reaktor dan mengeluarkannya secara terus menerus walaupun dengan kondisi reaktor sedang operasi. Di RSG-GAS terdapat total 5 rabbit sistem yang terdiri dari 4 rabbit dengan kecepatan transfer normal (rabbit sistem hidrolik) dan 1 rabbit sistem kecepatan tinggi (rabbit sistem pneumatik). Media transportasi yang digunakan terdiri dari air demineralisasi untuk hidrolik sistem sedangkan nitrogen untuk pneumatik sistem. Perbedaan kecepatan transfer berpengaruh pada perbedaan target iradiasi yang akan digunakan khususnya untuk keperluan AAN. Untuk target dengan waktu paruh panjang dapat digunakan RS hidraulik sedangkan untuk analisa target iradiasi dengan waktu paruh sangat pendek digunakan RS pneumatik ${ }^{[1]}$.

Laju transfer kapsul sampai dengan 10 $\mathrm{m} / \mathrm{s}$ adalah kinerja terbaik dari RS pneumatik. Kelajuan yang lebih tinggi, akan meningkatkan kerusakan target karena tumbukan antara kapsul dengan teminal iradiasi atau terminal cacah walaupun suplai udara bertekanan telah ditutup. Pergerakan/kelajuan kapsul terjadi karena perbedaan tekanan yang diberikan pada sisi upstream, yang artinya semakin tinggi tekanan yang diberikan sebanding dengan kelajuan kapsul, dengan massa yang sama maka akan semakin besar momentum yang diciptakan.
Oleh sebab itu dibutuhkan alat ukur kelajuan kapsul agar didapatkan nilai yang akurat antara tekanan suplai udara kering dan kelajuan yang terukur. Alat ukur kelajuan kapsul target ini terdiri dari dua pasang sensor optic dengan laser sebagai emitter dan photo transistor sebagai receiver. Penggunaan sensor optoelektronik seringkali digunakan untuk pengukuran kecepatan laju suatu benda [3][4][5]. Pengukuran kecepatan dari suatu benda yang bergerak terutama benda dalam lintasan dapat dilakukan menggunakan teknik pengukuran waktu layang / tunda ${ }^{[6]}$.

Sensor pengukur kecepatan dipasang terpisah sejauh 1 meter antara satu sama lain. Ketika kapsul melaju sensor akan memotong cahaya di sensor di bagian upstream, ketika kapsul memotong cahaya yang dipancarkan laser, photo transistor pada sisi receiver akan memberikan sinyal high, yang akan dikirim menuju input Timer. Sinyal tersebut akan mengambil nilai cacahan yang terjadi didalam mikrokontroler. Begitupun ketika kapsul menyentuk sensor pada bagian downstream. Kemudian kapsul akan menyentuh sensor kedua dan mengaktifkan sinyal untuk kembali mencuplik waktunya ${ }^{[7]}$. Mikrokontroler akan menghitung kecepatan laju kapsul dari jarak sensor terpisah dibagi dengan perbedaan waktu cuplik kedua sensor. Perbedaan nilai pencacahan merupakan representasi dari waktu tem puh antara kedua sensor. Sehingga kelajuan dari kapsul dapat ditentukan. Nilai penentuan kelajuan tersebut akan disimpan dalam suatu register dan ditampilkan pada layar LCD. 
Program Refungsionalisasi fasilitas saat ini masih terus dilakukan untuk meningkatkan pelayanan publik dan utilisasi reaktor. Pengembangan Pneumatics Rabbits System dimulai dengan pengujian pada semua sistem dan komponennya, sehingga diperlukan modifikasi pada sistem transfer target yang berdasarkan asas kepraktisan ${ }^{[2]}$. Perancangan Sensor Pengukur Kecepatan Kapsul ini diharapkan dapat diintegrasikan ke dalam Program Pengembangan Otomatisasi Sistem Pengirim Kapsul Pneumatik Rabbit di Reaktor RSG-GAS. Yang mana Program Pengembangan Sistem Rabbit Pneumatik menjadi salah program refungsionalisasi fasilitas yang sudah ditetapkan dalam RENSTRA PRSG Tahun 2015-2019.

\section{TEORI}

\section{Rabbit Sistem Pneumatik}

Pengoperasian RS pneumatik lebih difokuskan untuk keperluan AAN, khusunya untuk mengaktivasi sampel dengan paruh waktu yang sangat pendek. Saat ini RS pneumatik sedang dilakukan modifikasi untuk meningkatkan kualitas pelayanan. Modifikasi RS pneumatik ditunjukkan pada Gambar 1. RS pneumatik menggunakan kapsul dengan diameter $18 \mathrm{~mm}$ dan panjang $46 \mathrm{~mm}$. Berat maksimal kapsul dan sampel yang diizinkan adalah $10 \mathrm{gr}$. Laju transfer kapsul sebesar $10 \mathrm{~m} / \mathrm{s}$ pada tekanan 1,5 bar ${ }^{[1]}$. Target yang akan diiradiasi ditempatkan pada kapsul loader, program akan menginisialisasi, setelah operator menekan tombol untuk iradiasi, katup JBB05 AA016 akan membuka dan menghembuskan udara kering bertekanan, sehingga kapsul akan menuju posisi iradiasi pada kecepatan 10 $\mathrm{m} / \mathrm{s}$ pada tekanan udara 1,5 bar [2] Ketika kapsul menyentuh sensor posisi JBB05 CG001, katup JBB05 AA016 akan menutup. Kapsul akan menuju teras dengan jatuh bebas dan kecepatan awal pada saat suplai udara terputus. Kapsul berada di posisi iradiasi sesuai permintaan lama waktu iradiasi dari pelanggan. Selama kapsul diiradiasi terjadi pendinginan menggunakan media nitrogen. Ketika waktu iradiasi telah terlampaui, kapsul kembali dengan membalikan arah aliran nitrogen dengan konfigurasi solenoid valve JBB05 AA001AA004. 


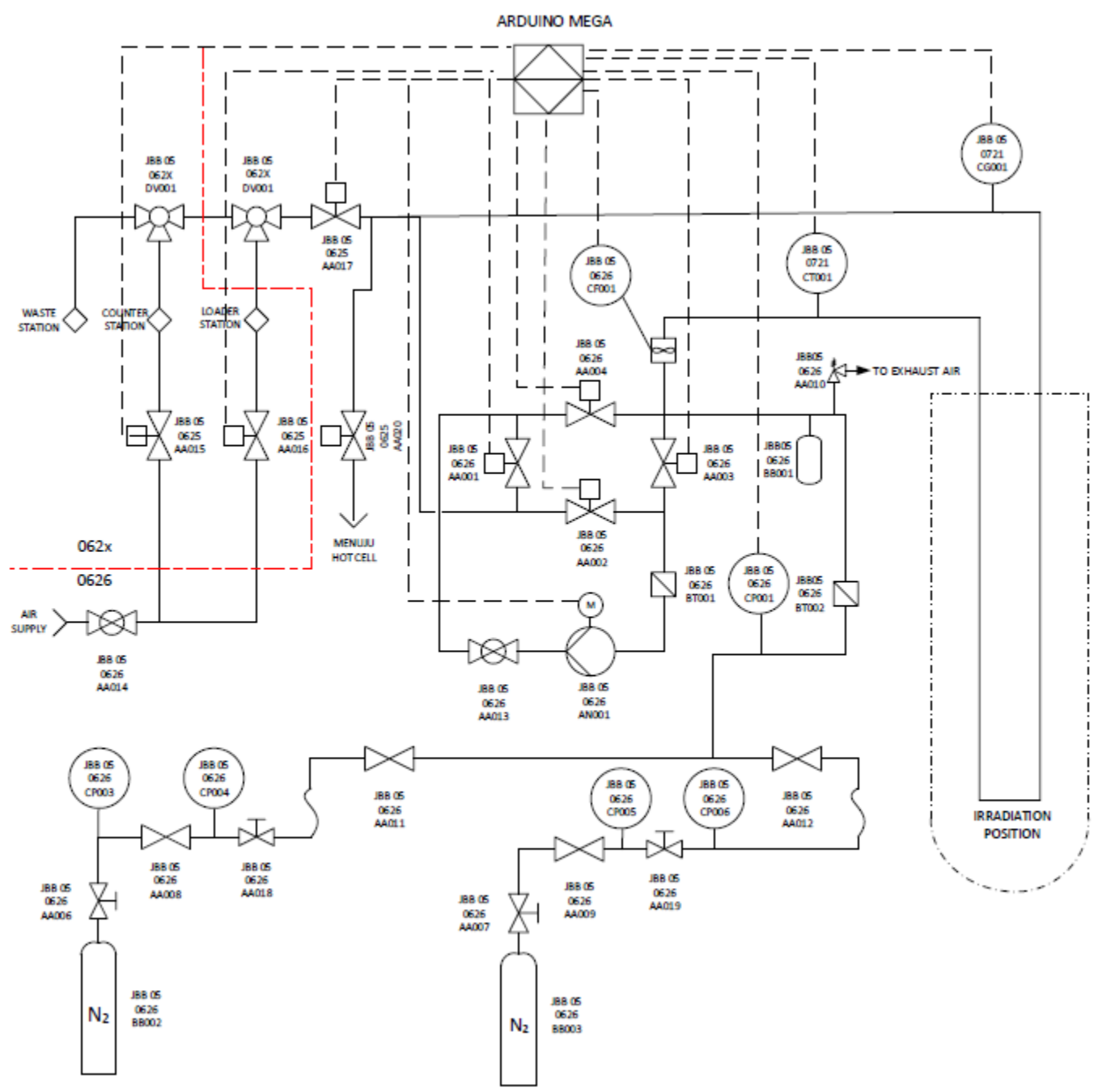

Gambar 1. Gambar perpipaan dan instrumentasi RS pneumatik ${ }^{[8]}$

Photo Elektrik Sensor

Metode dalam pengukuran posisi salah satunya adalah menggunakan photo electrik. Sensor terdiri atas sumber cahaya (emitter) dan penerima cahaya (receiver). Konfigurasi antara keduanya ditunjukan oleh Gambar 2. Pemilihan Sumber cahaya yang digunakan berdasarkan objek dan lingkungan yang diukur. Jangkauan laser mempunyai jangkauan cahaya yang lebih jauh, sedangkan agar tidak terganggu dengan cahaya tampak dapat digunakan sumber cahaya infrared (IR). Ada dua type Detektor cahaya atau receiver, yaitu photocell dan phototransistor. Keduanya bersifat konduktif, yang berarti konduktifitas elektrik sebanding dengan 
cahaya yang diserap. Phototransistor dan potodiaode adalah pasangan yang ideal untuk sumber IR LED, karena lebih sensitif terhadapa cahaya IR. Selain itu phototransistor/pohotodiode menpunyai respon lebih cepat dibanding dengan photocell $^{[9]}$.

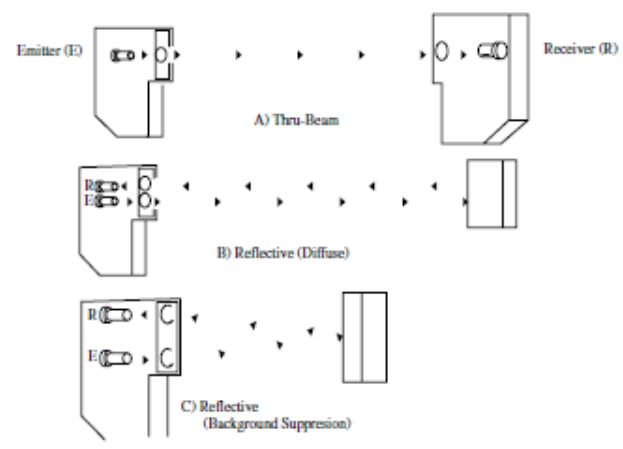

Gambar 2. Beberapa tipe pemasangan sensor optik ${ }^{[9]}$

Arduino

Arduino adalah jenis papan (board) yang berisi mikrokontroller. Arduino dilengkapi dengan sejumlah pin yang digunkan untuk berkomunikasi dengan peralatan lain. Arduino terdiri dari berbagai jenis, salah satunya adalah Arduino Mega 2560, yang dilengkapi dengan mikrokontroller ATMega 2560. Mikrokontroler dinamakan juga pengontrol tertanam (embedded controller). Mikrokontroler merupakan jenis integration circuit (IC) yang dapat diprogram. Program berfungsi untuk memberikan instruksi yang membuat arduino dapat melaksanakan tugas sesuai dengan instruksi-instruksi yang diberikan. Arduino dengan processor AVR ATMega 2560 dilengkapi pewaktu luar atau external clocking dengan frekuensi sebesar $16 \mathrm{Mhz}$, yang artinya Arduino mempunyai siklus waktu sebesar
16 juta setiap detik. Siklus waktu adalah waktu yang dibutuhkan untuk mikrokontroler dalam menjalankan 1 perintah/instruksi ${ }^{[10]}$.

\section{Penentuan Error}

Kemampuan dari alat pengukur kecepatan berbasis photonics tergantung dari seberapa akurasi perhitungan dari ToF dan jarak antara sensor. Kecepatan dari suatu benda yang diukur adalah rasio jarak antara sensor, ToF serta ketidakpastian dalam pengukuran kecepatan yang tergantung dari dua parameter tersebut ${ }^{[7]}$.

$S=\frac{X}{t_{0}}$

Dengan menambahkan logaritma natural terhadap persamaan 1diperoleh persamaan berikut :

$\log _{e} S=\log _{e} X-\log _{e} t_{0}$

Dengan diferensiasi dari persamaan 2 terhadap S, maka diperoleh persamaan 3 sebagai berikut :

$\frac{1}{S}=\frac{1}{X}\left(\frac{d X}{d S}\right)-\frac{1}{t_{0}}\left(\frac{d t_{0}}{d S}\right)$

$\frac{d S}{S}=\frac{d X}{X}-\frac{d t_{0}}{t_{0}}$

Representasi error untuk $X$ adalah $\pm \frac{d X}{X}$, dan $t_{0}$ adalah $\pm \frac{d t_{0}}{t_{0}}$, dengan assumsi menentukan error terbesar maka persamaan 3 menjadi :

$\frac{d S}{S}=\frac{d X}{X}+\frac{d t_{0}}{t_{0}}$

Keterangan :

$$
\begin{array}{ll}
\mathrm{S} & =\text { Kecepatan } \\
\mathrm{X} & =\text { jarak } \\
\mathrm{t} & =\text { waktu }
\end{array}
$$




\section{METODE}

Perancangan alat ukur laju kapsul RS pneumatik dilakukan dengan beberapa tahapan:

1. Perancangan perangkat keras

2. Perancangan perangkat lunak

3. Simulasi

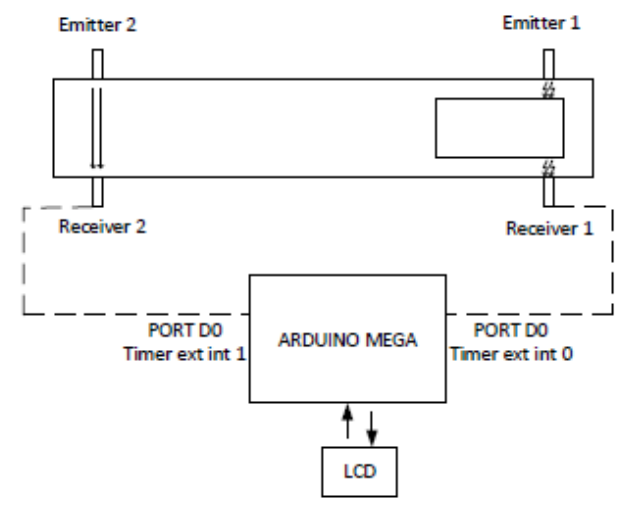

Gambar 3. Diagram blok rancangan alat ukur kecepatan kapsul pneumatik

Perancangan Perangkat Keras menggunakan modul sensor cahaya dengan pemancar berupa laser dan penerimanya yang terpasang pada dudukan/mounting berupa kopling. Diameter luar dudukan sensor $60 \mathrm{~mm}$, dengan lubang sebesar diameter dalam pipa yaitu 19,40 mm. Lubang O-Ring Seal sebesar $35,20 \mathrm{~mm}$, sedangkan lubang sensor sebesar $5 \mathrm{~mm}$ dibuat drat [11]. Sensor yang digunakan untuk mendeteksi kapsul adalah sensor autonic seri BF3 RX dengan amplifier yang digunakan seri BF4. Sinyal yang diberikan oleh sensor ketika kapsul melewatinya akan dikirim menuju transduser dan akan mengubah menjadi bentuk sinyal kotak HIGH. Sinyal dari transducer akan dikondisikan dengan modul pembagi tegangan agar masukan yang keluar sesuai dengan wilayah kerja dari mikrokontroler yaitu sebesar (1 - 5) volt. Mikrokontroler mengolah sinyal dan mengirimkan data kecepatan yang sudah diproses ke PC untuk ditampilkan melalui komunikasi serial/USB. Blok diagram perancangan ditunjukkan oleh gambar 4 .

Perangkat keras yang digunakan untuk sistem pengukur laju kapsul ini

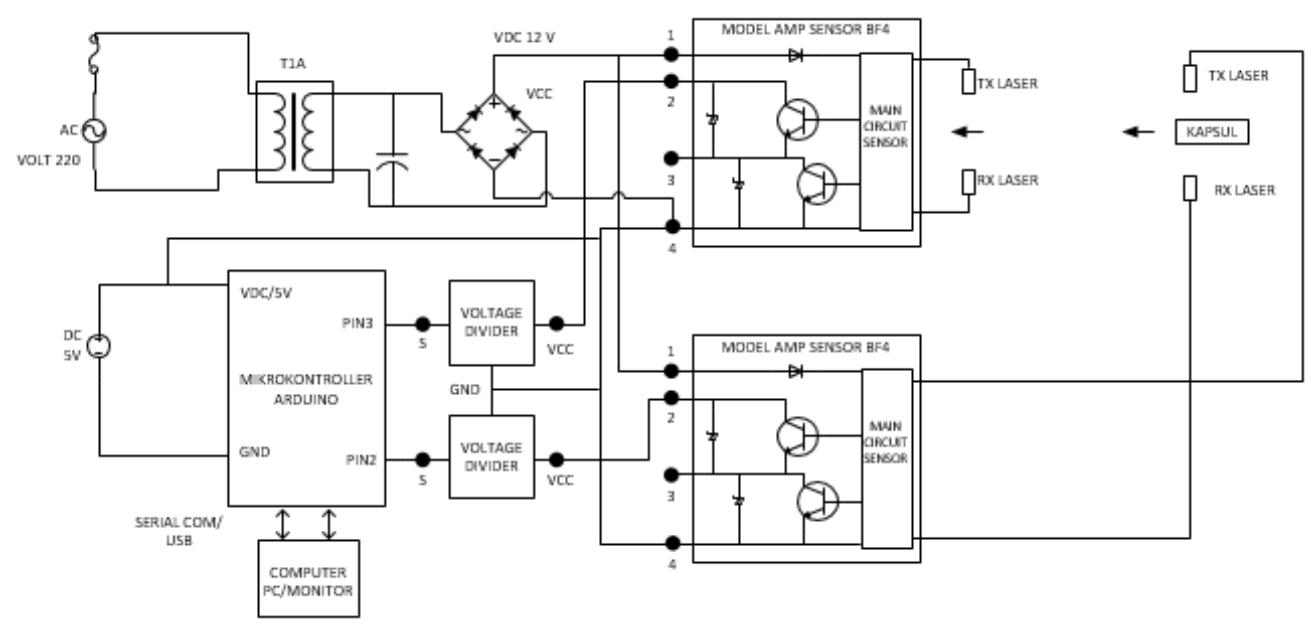

Gambar 4. Blok diagram rancangan alat ukur kecepatan kapsul pneumatik 


\section{Perancangan Perangkat Lunak}

Perangkat lunak diperlukan agar Arduino dapat mengolah data-data atau sinyal masukan dari sensor dan mengeluarkannya sebagai sebuah informasi atau sinyal kendali. Perangkat lunak yang dirancang akan dibuat dan dimasukkan/download ke dalam perangkat keras dengan bantuan software antarmuka yang telah disediakan oleh Arduino, yaitu Arduino IDE yang berbasis bahasa C. Berikut adalah diagram alir program alat pengukur kecepatan kapsul RS pneumatik.

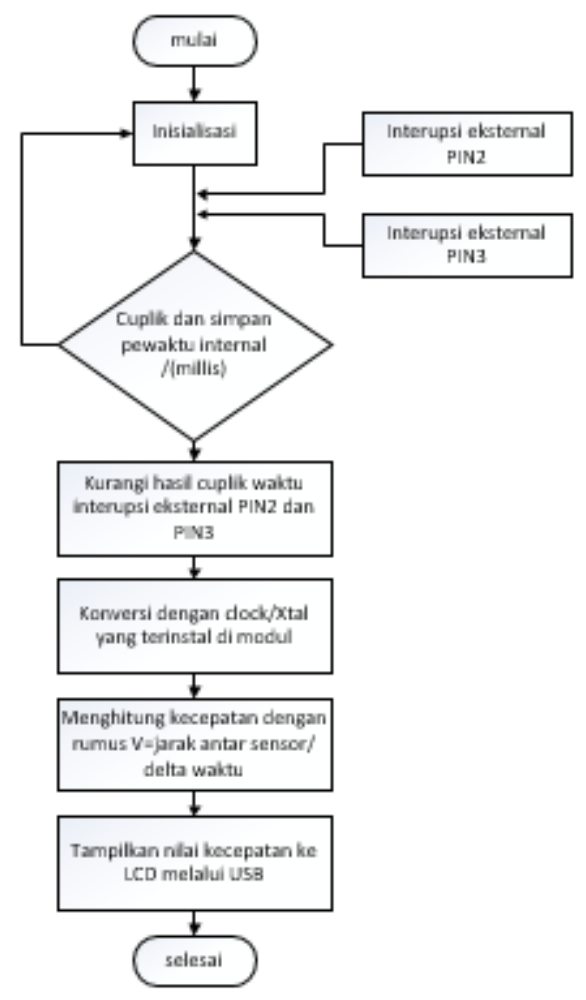

Gambar 5. Diagram alir rancangan alat ukur kecepatan kapsul pneumatik

\section{Simulasi}

Software yang dirancang, kemudian akan disimulasikan menggunakan software PROTEUS 8.0. Simulasi berfungsi untuk mengetahui apakah program yang dirancang akan bekerja seperti yang diinginkan. Simulasi dilakukan dengan mengganti rangkaian sensor menjadi dua buah push button. Gambar 6 . menunjukkan simulasi yang dilakukan menggunakan PROTEUS 8.0. Simulasi dilakukan dengan menekan kedua tombol/push button secara bergantian, sehingga didapatkan nilai kecepatannya. 


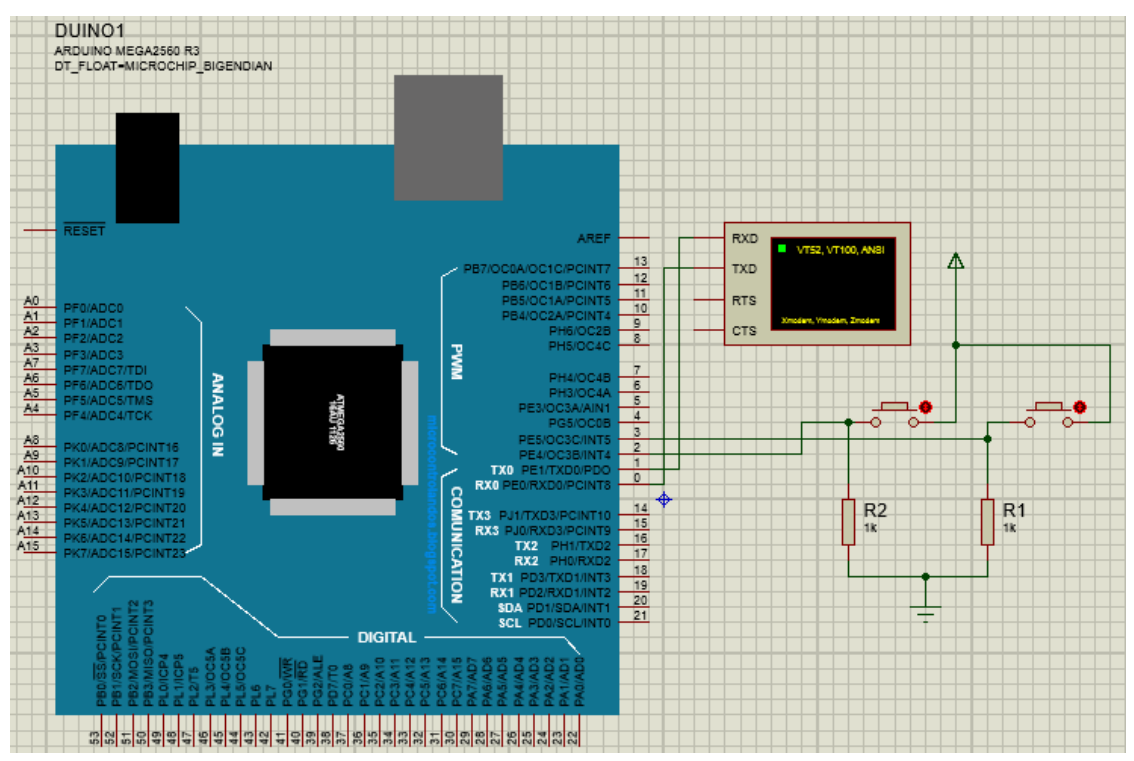

Gambar 6. Skematik simulasi rancangan alat ukur kecepatan kapsul pneumatik

\section{HASIL DAN PEMBAHASAN}

Hasil simulasi menggunakan proteus dari tahap perancangan yang telah dilaksanakan, diperoleh hasil berupa data kecepatan selama 10 kali percobaan. Berikut ini adalah tabel data hasil pengujian program alat ukur kecepatan kapsul RS pneumatik.

Tabel 1. Hasil simulasi rancangan alat ukur kecepatan kapsul pneumatik

\begin{tabular}{|c|c|c|c|c|c|}
\hline \multirow{2}{*}{ No. } & \multicolumn{2}{|c|}{$\begin{array}{c}\text { Nilai cacah internal Arduino } \\
(\mu \mathrm{S})\end{array}$} & $\begin{array}{c}\text { Selisih waktu }(\mathrm{t}) \\
\text { (sensor2-sensor1) }\end{array}$ & $\begin{array}{c}\text { nilai } \\
\text { kecepatan }(\mathrm{v})\end{array}$ & $\begin{array}{c}\text { Error S } \\
d S\end{array}$ \\
\cline { 2 - 6 } & Sensor 1 & Sensor 2 & 400000 & 2,5250 & 0,0187 \\
\hline 1. & 1342416 & 1742416 & 300000 & 3,3667 & 0,0221 \\
\hline 2. & 3052396 & 3352396 & 298952 & 3,3785 & 0,0222 \\
\hline 3. & 4897580 & 5196532 & 250000 & 4,0400 & 0,0239 \\
\hline 4. & 6696532 & 6946532 & 250000 & 4,0400 & 0,0239 \\
\hline 5. & 8306700 & 8556700 & 450000 & 2,2444 & 0,0172 \\
\hline 6. & 1213882 & 1258882 & 200000 & 5,0500 & 0,0248 \\
\hline 7. & 1378882 & 1398882 & 300000 & 3,3667 & 0,0221 \\
\hline 8. & 1751093 & 1781093 & 282560 & 3,5745 & 0,0228 \\
\hline 9. & 2142076 & 2170332 & 350000 & 2,8857 & 0,0203 \\
\hline 10. & 2742861 & 2777861 & & & \\
\hline
\end{tabular}


Nilai kecepatan adalah hasil dari perhitungan yang ditunjukkan oleh persamaam 1. Dengan asumsi jarak antara kedua sensor sebesar 1 meter dan asumsi toleransi sebesar $\pm 0,01$. Ketika sensor 1 atau push button 1 ditekan, kaki no. 2 pada Arduino ATMega mendeteksi adanya perubahan sinyal dari LOW menuju HIGH yang mengaktifkan interupsi eksternal dan menjalankan program untuk mencuplik waktu/timer internal yang selalu mencacah. Pada percobaan 1, waktu cuplikan yang diambil bersamaan dengan perubahan logika pada pin no. 2 adalah 1342416 yang artinya, program telah berjalan selama 1342416 mikrodetik sejak mikrokontroler mendapatkan daya dan menjalankan program. Nilai cuplikan ini disimpan dalam register "nilai1". Hal yang sama terjadi pada pin no 3 , ketika tombol ditekan dideteksi sinyal naik, yang mengaktifkan pencuplikan timer internal dan disimpan pada register "nilai2" dengan waktu 1742416 microdetik. Selisih antara register "nilai1" dan "nilai2" menggambarkan perbedaan waktu ketika kapsul melewati sensor 1 dan sensor 2 . Sehingga kecepatan kapsul dapat dihitung menggunakan persamaan 1 dan didapatkan hasil seperti ditunjukan Tabel 1. Keakuratan dari sebuah alat ukur menjadi tolok ukur baik tidaknya sebuah alat ukur. Pada alat yang dirancang ini faktor keakuratannya yaitu pada keakuratan dari sensor optik yang digunakan dan respon dari mikrokontroler setelah menerima sinyal dari sensor [cost efective]. Sensor yang digunakan adalah laser sensor dan amplifier AUTONICS BF4R series, dengan response max 0,5 ms. Mikrokotroller yang digunakan adalah
Arduino ATMega2650 dengan $16 \mathrm{MHz}$ oscilator atau dengan kata lain mikrokontroler mempunyai kemampuan mengerjakan tiap langkah program dengan kecepatan 0,0625 mikrodetik. Penggunaan timer internal berupa library micros yang mempunyai resolusi sebesar 4 нs.

Dari 10 percobaan simulasi pada Tabel 1. Juga menunjukkan kecenderungan kenaikan error sebanding dengan kenaikan kecepatan. Mengacu pada persamaan 1 besarnya error kecepatan sangat dipengaruhi dengan besarnya error pada elemen $\frac{d t_{0}}{t_{0}}$ pada persamaan 4 , dengan faktor pembagi yang semakin kecil, akan menyumbangkan error yang semakin besar. Sehingga memperbesar nilai dari $t_{0}$ akan memperkecil nilai error. Hubungan antar error total dan Time of Flight (ToF) ditunjukkan oleh Gambar 7.

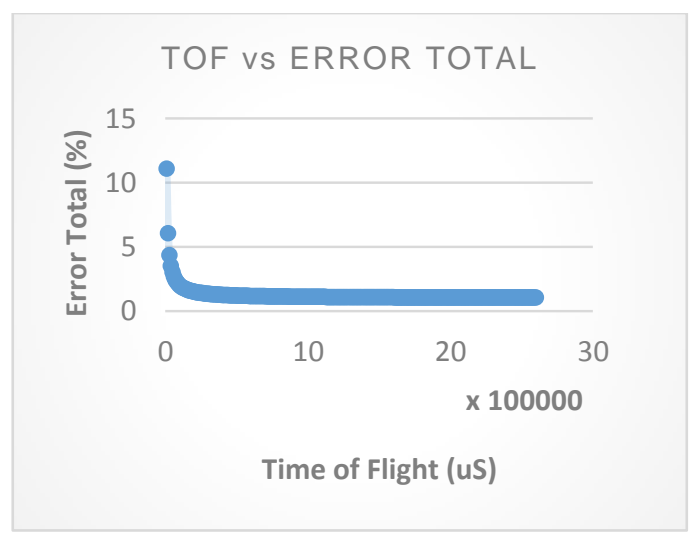

Gambar 7. Grafik perbandingan Waktu Tunda (ToF) vs Error Total pengukuran 


\section{KECEPATAN PENGUKURAN VS ERROR}

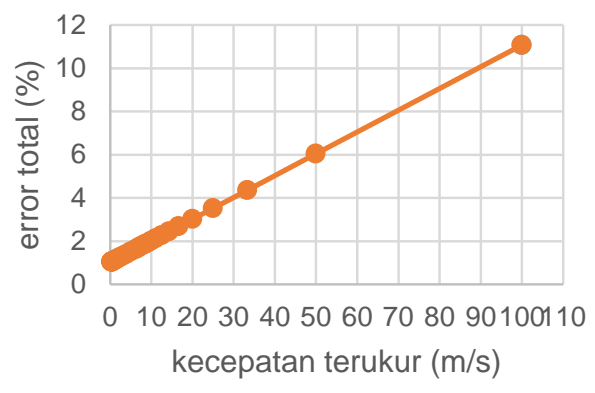

Gambar 8. Grafik perbandingan kecepatan terukur (m/s) vs Error Total $(\%)$

Grafik Error versus ToF menunjukkan semakin cepat objek bergerak yang ditandai semakin pendek waktu transisi antara sensor 1 dan sensor 2, maka semakin besar juga error yang diberikan oleh alat ukur. Meningkatnya nilai error tesebut disebabkan semakin kecil selisih waktu transit (ToF) antara yang diberikan oleh sensor bersifat tetap yaitu max 0,5 mikrodetik. Error sangat dipengaruhi dengan waktu tunda pembacaan sensor 1 dan 2 (ToF), sehingga semakin lama waktu tunda akan meningkatkan ketelitian pembacaan. Untuk memperlama waktu tunda dapat dilakukan dengan meningkatkan jarak antara sensor 1 dan sensor 2 .

Mengacu pada Gambar 8 kenaikan error total naik secara linear dengan kecepatan terukur, pada saat kecepatan transfer kapsul $10 \mathrm{~m} / \mathrm{s}$ maka error pembacaan sebesar $2 \%$.

\section{KESIMPULAN}

Perancangan Sensor Pengukur Kecepatan Kapsul Iradiasi Pneumatik di Fasilitas Rabbit Sistem Pneumatik, menggunakan sensor laser BF3 dan BF4 series, dengan Arduino ATMega2650 sebagai antarmuka pengolah datanya. Dari simulasi sensor pada program PROTEUS 8.0 diperoleh data, kemudian dilakukan pengolahan. Hasil dari pengolahan data diperoleh error sebesar $2 \%$ pada saat kecepatan kapsul $10 \mathrm{~m} / \mathrm{s}$. Untuk mengurangi nilai error dapat dilakukan dengan memperpanjang jarak lintas antara sensor 1 dan sensor 2 . Perancangan perangkat ini dapat diimplementasikan dan diintegrasikan pengembangannya lebih lanjut ke dalam sistem yang sedang dibangun saat ini, yaitu : Otomatisasi Sistem Pengirim Kapsul Pneumatik Rabbit di Reaktor RSG-GAS.

\section{DAFTAR PUSTAKA}

1. Interatom. Operation and Maintenance Manual. -. p. 1-41.

2. Sutrisno, Suwoto. Rancangan Alat Bantu Pengirim Kapsul pada Sistem Pneumatik Rabbit di Reaktor RSGGAS. Prosiding Seminar Nasional Teknologi dan Aplikasi Reaktor Nuklir. 2012: (138-142).

3. Sánchez-Pena JM. Cost-effective optoelectronic system to measure the projectile velocity in high-velocity impact testing of aircraft and spacecraft structural elements. Opt Eng [Internet]. 2007;46(5):051014. Available from: http://opticalengineering.spiedigitallibr ary.org/article.aspx?doi=10.1117/1.27 40771

4. Yanti N, Yulkifli, Kamus Z. Pembuatan Alat Ukur Kelajuan Angin menggunakan Sensor Optocoupler dengan Display PC. J Sainstek. 2015;7(2):95-108. 
5. Nisa C, Widya P. N, Santosa A, Rahmawati E. Perancangan Instrumentasi Pengukur Waktu Dan Kecepatan Mengunakan DT-Sense Infrared Proximity Detector Untuk Pembelajaran Gerak Lurus Beraturan. J Pendidik Fis dan Apl. 2014;4(1):3641.

6. Kumar D, Gaur A, Meerut R. " $\mathrm{HIGH}$ SPEED PROJECTILE RECORDING SYSTEM ." Int J Sci Eng Res. 2012;3(10):1-5.

7. Dhanda R, Khatri N, Jaglan D. Microcontroller Based Electronic Clock for the Measurement of Time of Flight Microcontroller Based Electronic Clock for the Measurement of Time of Flight ( ToF ) Of High Speed Objects Department of ECE N . C . College of Engineering. Int J Eng Res Technol. 2012;1(5 July).
8. Liptak B. INSTRUMEN ENGINEER HANDBOOK 4th Edition Process measurement and analysis. Strain. New York; 2003. 965-969 p.

9. Kadir A. Buku Pintar Pemrograman ARDUINO. Yogyakarta: Andi Publisher; 2015. 518 p.

10. Sunarko, Ali H, Sufmawan A. Rancang Bangun Driver Katup Solenoid Sistem Pengirim Kapsul Pneumatic. Prosiding Seminar Nasional Teknologi dan Aplikasi Reaktor Nuklir Tahun 2016. 2016;118-24. 